\title{
The system approach to innovative development of regional foodstuff market in conditions of crisis
}

According to the bases of a state policy of the Russian Federation in the field of healthy food for the population for the period till 2020, the purposes of a state policy in this field are: preservation and strengthening of health of the population as well as preventive maintenance of the diseases caused by a defective and unbalanced diet.

In the conditions of crisis the nutrition of the majority of adult population of the Russian Federation does not correspond to the principles of healthy food because of consumption of the foodstuff containing a considerable quantity of animal fats and simple carbohydrates, and lack of vegetables and fruit, fish and seafood in a diet. It leads to the growth of superfluous weight of body and the adiposity, which prevalence for the last 8-9 years has increased from 19 to $23 \%$, increasing the risk of development of diabetes, diseases of cardiovascular system and other diseases.

The considerable part of working population is deprived of possibility to eat correctly in working hours. It concerns especially the small and average enterprises that adversely affect health of the working.

Death rate from the chronic illnesses which development is substantially connected with the alimentary factor, remains considerably higher than in the majority of the European countries.

It all testifies to necessity of development of the programs directed to optimize the population's diet.

One of the primary goals of a state policy in the field of healthy food is developing the manufacture enriching the products with irreplaceable components, producing specialized products for babies, products of a functional purpose, dietary (medical and preventive) foodstuff and biologically active additives to food, including the ones used in food for the organized collectives.

It is expected, that manufactured products of mass consumption enriched with vitamins and mineral substances, including mass grades of bakery products and as dairy products, will increase to $50 \%$ of the total amount of the manufacture.

It is required that in the conditions of crisis some system approach is found to solve the problem of developing innovative market of foodstuff .

Efficient control of the consumer market of foodstuff can be considered a key direction of economic development of Irkutsk region. This market is strategically important for 
forming human capital of the region, as food is a basis for preservation and maintenance of population's health.

The following conditions of currently consumed food may lead to the development of various diseases:

- a superfluous consumption level of animal fats and carbohydrates;

- the deficiency of folic acid, vitamin C, group B vitamins, selenium, iodine, iron as well as deficiency of food fibres.

Huge influence on health of the population and occurrence of the diseases render prime environmental conditions of the resided territories. There are some specific conditions of Pribaikalye region that may lead to development of certain illnesses. It is necessary to note the negative influence of low temperatures creating the preconditions of developing coldrelated diseases; the long winter promotes the development of avitaminosis; the low levels of vital minerals and microcells in soil as well as the use by the population of ultrafresh Baikal water cause the development of a microelement disbalance.

Preconditions of gross infringements to health of the population of Pribaikalye region is created by anthropogenous environmental contaminations (technogenic loading on an organism). In connection with wide development in the region of fuel and energy, pulpand-paper, woodworking industry and nonferrous metallurgy, negative influence of adverse natural factors is aggravated by technogenic pollution of the environment.

Natural and anthropogenous factors of Pribaikalye cause changes in numbers of inhabitants and create the conditions to occurrence of various diseases connected to lack, surplus and disbalance of microcells.

Therefore the questions of preventive maintenance of deficiency of microcells remain a priority line of activity for today and should result in formation of the system approach to innovative development of the regional market of foodstuff.

The economic crisis has been negatively reflected in functioning of the food market and it is caused by the factors having both internal and external character.

Thus, increasing the cost of some kinds of foodstuff has negatively affected consumers' demands, as the incomes of population in the conditions of crisis are at the same time decreasing. The structure of production and sells of foodstuff has also changed. While retail prices were growing, the wholesale ones (for the peasants) were decreasing. Lack of coordinated communication between manufacturers and consumers interfered the process of replacing imported goods by domestic production. Due to long procedure of registration of credits and insufficiency or absence of pledge, the possibilities of small business were limited in subsidizing programs.

In the conditions of economic crisis, the primary task of the enterprises of foodprocessing industry should be aspiring to innovative development as well as decreasing the expenses for manufacturing and selling competitive products.

Innovative development of regional consumer food market is impossible without the system approach based on effective interaction between the regional state bodies and manufacturers with the view of satisfying the demands of consumers in the best way.

The basic problems containing growth of the Irkutsk regional market of foodstuff in the conditions of crisis, are:

- high physical deficiency and an obsolescence of the basic industrial funds;

- slow introduction of innovative technologies in manufacture.

The problems mentioned above are caused by the absence of: 
a) the institutes of innovative development of the enterprises of the food-processing industry providing interesting interaction of scientific, industrial, social, state and commercial financially-credit structures in creation and use of progressive technologies;

b) the mechanism of stimulating enterprises making foodstuff to create, develop and use new progressive technologies;

c) strong technological base for manufacturers of foodstuff;

d) effective systems of technological management.

The system of innovative development of manufacture of foodstuff in the Irkutsk region should cover all kinds of works at enterprise level, on the basis of uniform methodology and the territorial technological policy.

In connection to this, there is a necessity:

- To create, develop and widely use the progressive innovative technologies in all kinds of industrial-economic activities in the food-processing industry;

- To work out the national standards providing observance of requirements of technical regulations concerning foodstuff and raw food materials;

- To create the system of accounting and monitoring the technologies and technological development of manufacturing food, and monitoring the conditions of food quality among population;

- To maintain legislatively the conditions for investments into manufacturing of products of mass consumption enriched with vitamins and mineral substances as well as functional purpose products;

- To create scientific regional research centers in the field of modern biotechnological ways of receiving new sources of food and a medical and biological estimation of their quality and safety.

On an example of the Irkutsk region the special model of choice of innovative technologies has been developed. The model concerns the technologies of enriching the food with microcells in the region scarce on iodine. The model is used for calculating the size of the investments directed on compensating for the expenses of the enterprises, letting out the products enriched with iodine and accompanying microcells.

The coordinated state investment program of enriching the foodstuff with necessary microcells should consider the following conditions:

1) The program should be focused on covering all population with differentiation on such groups as: children, able-bodied population, pensioners;

2) The minimal amount of the first demand foodstuff necessary for the person to live should be based on the norms provided by a regional consumer's basket counted for all population of the region taking into account a background component of the microcell and considering potential enriching the products with microcells;

3) To minimize the expenses of enriching the quality of food it is necessary to use more effective components of an organic origin.

The system approach should provide coordination of informational, technological, financial, organizational and legal components of innovative process.

The innovative development of regional consumer food market should be aimed at solving economic and social problems of the region with the purpose of protecting the rights and interests of manufacturers and consumers. Such an approach will allow to provide an effective functioning of this sector of economy which will be positively reflected in forming a high quality human capital. 


\section{The system approach to innovative development of regional foodstuff market in conditions of crisis}

Efficient control of the consumer foodstuff market can be considered a key direction of economic development of Irkutsk region. This market is strategically important for forming human capital of the region, as food is a basis for preservation and maintenance of population's health.

The economic crisis has been negatively reflected in functioning of the market of foodstuff that is caused by the factors having both internal and external character.

Increasing the cost of some kinds of food has negatively affected consumers' demands, as the incomes of the population in the conditions of crisis are decreasing. The structure of production and sells of foodstuff has changed. While retail prices are growing, the wholesale ones (for the peasants) are decreasing. The lack of coordinated communication between manufacturers and consumers interfered with the process of replacing imported goods with domestic products. Due to long procedures of registration for credits and insufficiency or absence of pledge, the possibilities of small businesses were limited in subsidizing programs.

In the conditions of economic crisis, the primary task of the enterprises of food-processing industry should be aspiring to innovative development as well as decreasing the expenses for manufacturing and selling competitive products.

Doc. Elena Gafarova

Irkutsk State Technical University, Russia

e-mail: persik17@mail.ru 